\title{
Investigation of Process Parameters Effect on Anisotropic Properties of 3D Printed Sand Molds
}

\author{
Nicolas CONIGLIO*, Tharmalingam SIVARUPAN, Mohamed EL MANSORI \\ MSMP Laboratory, EA-7350, Arts et Metiers ParisTech, \\ 2 Cours des Arts et Metiers, 13617 Aix en Provence, France
}

\begin{abstract}
The development of sand mold three-dimensional printing technologies enables the manufacturing of molds without the use of a physical model. However, the effects of the three-dimensional printing process parameters on the mold permeability and strength are not well known, leading the industries to keep old settings until castings have recurring defects. In the present work, the influence of these parameters was experimentally investigated to understand their effect on the mold strength and permeability. Cylindrical and bar-shaped test specimens were printed to perform respectively permeability and bending strength measurements. Experiments were designed to statistically quantify the individual and combined effect of these process parameters. While the binder quantity only affects the mold strength, increasing the recoater speed leads to both greater permeability and reduced strength due to the reduced sand compaction. Recommendations for optimizing some 3D printer settings are proposed to attain predefined mold properties and minimize the anisotropic behavior of the sand mold in regards to both the orientation and the position in the job box.
\end{abstract}

Keywords: 3D printing; mold properties; casting; additive manufacturing

\section{Nomenclature :}

3DP Three-dimensional printing

3PB Three-point bending

$\mathrm{P}_{\mathrm{x}} \quad$ Permeability along $\mathrm{X}$-direction

$\mathrm{P}_{\mathrm{y}} \quad$ Permeability along Y-direction

$\mathrm{P}_{\mathrm{z}} \quad$ Permeability along Z-direction

\footnotetext{
* Corresponding author: nicolas.coniglio@ensam.eu
} 
$\sigma_{\mathrm{y}} \quad$ Stress along Y-direction

$\rho$

Density

\section{INTRODUCTION}

The development in additive manufacturing also referred to as three-dimensional (3D) printing technology, provides technological means to fabricate near-net-shaped three-dimensional parts, as indicated in reviews on the subject [1-6]. Particular 3D printers are used to manufacture sand molds for casting, directly from computer models [4-20]. While dimensional accuracy is the main concern due to squashing [11,21-24], other sand mold properties such as density [25], permeability [15], and strength $[9,15,25-27]$ remain difficult to control homogeneously over the volume of the printed parts. Sand mold designs for foundry purposes may include a high permeability for filling enhancement, a sand binder with low volatile content for porosity defect avoidance, an excellent dimensional accuracy for limited post-casting machining, and sufficient strength for easier handling [28].

Permeability refers to the ability of a mold volatiles to escape without being a source of concern and is, therefore, a measure of the ease with which a mold gas can flow through the porous sand mold media [28]. A high mold permeability allows the escape of gases, reducing the outgassing pressure ahead of the molten front, and subsequently improving filling ability. Permeability relies in part on the sand grain compaction, with low compaction resulting in greater intergrain spacing and subsequently high permeability [12]. Therefore, high permeability conditions imply a probability of metal penetration defect due to the large inter-sand grain spacing.

A high mold strength permits good dimensional control of the casting during cooling, by limiting distortion, but may enhance hot tearing, by hindering the free contraction of the solidifying metal $[16,17,28]$. The sand mold strength depends upon the sand grain compaction and the binder amount $[12,26]$, with greater strength for greater sand grain compactions and binder amounts. However, the excessive use of binder produces too much off-gazing pressure ahead of the molten front during filling, generating poor casting quality [5] and lack of filling [29] .

Sand grain compaction is a common parameter that controls both strength and permeability. While numerous compacting methods have been developed [30], there are today issues in homogeneously compacting the sand grains within the same job box. Moreover, as greater compaction simultaneously reduces permeability and increases strength, the dependence of these two properties, upon the same 
condition, renders rather difficult the control of these two properties simultaneously. Post-printing solutions have been, therefore, proposed to obtain given mold properties by optimized mold curing conditions $[4,15]$.

Among the various existing binders, foundries commonly use the organic furan binder in 3D printing machines for the mold manufacturing to cast light alloys [5,11,14,16,17,31]. A 3D printer manufactures molds by successive layers of deposited sand with the addition of a controlled amount of resin at the future mold positions. The furan binder poses advantages related to its room-temperature curing and high mechanical strength [31]. While some studies investigated the process parameter effects on mold properties[12,26] [11], only one [11] quantified the heterogeneous properties of sand molds within the same job-box. Moreover, few published on the properties of furan sand molds printed by ExOne 3D printer [5,14].

The present work investigates the influence of print resolution, recoater (also referred to as sand conveyor) speed, and job-box position on the strength and permeability of sand molds. Experiments were statistically designed to quantify the individual and combined effect of process parameters on. Tests were carried out by printing three-point bending and permeability specimens at various positions in the job box. Statistical analysis was finally applied for selecting the appropriate 3D printer settings.

\section{EXPERIMENTAL SETUP}

\section{$3 D$ Printing process}

The sand mold samples were printed by a binder, furan, jetting printer ${ }^{\dagger}$ equipped with an $800 \times 500 \times 400 \mathrm{~mm}^{3}$ job box. The printing process began by mixing of the sulfonic acid catalyst and magnesium inhibitor ${ }^{\ddagger}$ with $8 \mathrm{~kg}$ of sand particles and temporally stored in the mixing chamber. Sand layers of $280 \mu \mathrm{m}$ thickness were successively deposited on the job box. Then the platform was lowered by a distance equal to the layer thickness before spreading the furfuryl alcohol based binder by the printhead inkjet nozzles on specific area according to each slice (cross section) in the STL file of the part to be printed. The process continued until the last slice of the samples was printed. The printed sand parts were cured at room temperature, inside the job box, for an hour before they were

\footnotetext{
${ }^{\dagger}$ ExOne S-Print ${ }^{\mathrm{TM}}$

$\$$ In order to imitate the use of the mold for the Mg alloy casting.
} 
taken out of the job box and the loose sand particles were removed with a soft brush or compressed air.

\section{Printing parameters}

The experimental setup was same as in the previous publication [32]. Briefly, a job-box (Fig 2) was designed in a commercial software program, $\mathrm{NetFabb}^{\mathrm{TM}}$, so as to characterize the sand specimens from various job-box positions, indicated as $\mathrm{X}_{\mathrm{i}} \mathrm{Y}_{\mathrm{j}}$ with $\mathrm{i}$ and $\mathrm{j}$ the $\mathrm{X}$ and $\mathrm{Y}$ coordinates, respectively. A total of 32 bars and 36 cylinders were printed each time (Table 1), and the respective tests were carried out. Printings were performed in a room maintained at a temperature of $298 \pm 3 \mathrm{~K}$ and relative humidity of $40 \pm 10 \%$. The print resolution (or furan drop spacing) and the recoater speed were varied (Table 2). Printed specimens may sink during compaction due to squashing if unbound sand particles are present underneath the printed specimens $[21,22,24]$. Therefore, to improve the repeatability by avoiding this issue, the specimens were always printed over the first $1.4 \mathrm{~mm}$ thick sand layer deposited in the jobbox bottom, thin enough to neglect compressibility issues and sub-layer displacements [21].

Table 1 : Dimensions, quantity, and orientations of specimens printed in each job box.

\begin{tabular}{|c|c|c|c|}
\hline Specimen & Dimensions (mm) & Direction & Number \\
\hline \multirow{2}{*}{$\begin{array}{c}\text { Bar } \\
\text { (for 3PB test) }\end{array}$} & \multirow{2}{*}{$22.4 \times 22.4 \times 172$} & $\mathrm{X}$ & 18 \\
\hline & & $\mathrm{Y}$ & 14 \\
\hline \multirow{3}{*}{$\begin{array}{c}\text { Cylinder } \\
\text { (for permeability test) }\end{array}$} & \multirow{3}{*}{$\begin{array}{c}\text { Diameter }=50 \\
\text { Height }=50\end{array}$} & $\mathrm{X}$ & 12 \\
\hline & & $\mathrm{Y}$ & 12 \\
\hline & & $\mathrm{Z}$ & 12 \\
\hline
\end{tabular}

Table $2: 3 \mathrm{D}$ printing process parameters for the sand specimens.

\begin{tabular}{|l|l|}
\hline Average sand grain size & $140 \mu \mathrm{m}$ \\
\hline Activator content & $0.18 \mathrm{wt} . \%^{\S}$ \\
\hline Inhibitor content & $0.4 \mathrm{wt} . \%^{* *}$ \\
\hline Print head voltage & $78 \mathrm{~V}$ \\
\hline Layer thickness & $280 \mu \mathrm{m}$ \\
\hline Heating temperature & $305 \mathrm{~K}$ \\
\hline Print resolution & $120-140 \mu \mathrm{m}$ \\
\hline Recoater speed & $130-286 \mathrm{~mm} \cdot \mathrm{s}^{-1}$ \\
\hline
\end{tabular}

\section{Specimen Characterization}

The three-point bending tests were carried out on the printed sand bars. The test fixture ${ }^{\dagger \dagger}$ (Fig. 3b), consisted of two supporting pins at $150 \mathrm{~mm}$ distance apart. A third pin applied a load at a rate of 0.1

\footnotetext{
$\S$ Of the sand weight.
}

** Of the sand weight. 
MPa.s ${ }^{-1}$, at the mid-length of each specimen, using an electric motor with a maximum load capacity of $12.8 \mathrm{MPa}$. The reading uncertainity on the pressure gauge was $\pm 0.05 \mathrm{MPa}$.

The mold permeability measurement was performed on the cylindrical specimens using a digital permeability meter ${ }^{ \pm t}$ with a measuring range from 0 to 1000 GP with \pm 1 GP uncertainity. The orifice standard method was applied as per the recommendations of American Foundry Sociey (AFS). The gas permeability ${ }^{\S}, G P$, was given by:

$$
G P=\frac{Q \times h}{S \times p \times t}
$$

, where $Q$ is the air volume in the chamber $\left(2000 \mathrm{~cm}^{3}\right), h$ is the height $(5 \mathrm{~cm})$ of the specimen (Fig. $3 \mathrm{a}), S$ is the specimen cross sectional area $\left(19.63 \mathrm{~cm}^{2}\right)$, and $t$ the passage time for the $2000 \mathrm{~cm}^{3}$ of air (in minutes).

The density was measured on the mold sample with maximum volume, that was the volume of a cylinder $\left(98.13 \mathrm{~cm}^{3}\right)$ to average the sand packing errors from printing process. The porosity was then evaluated by :

$$
\operatorname{Porosity}(\%)=\left(1-\frac{\text { apparent density }}{\text { bulk density }}\right) \times 100
$$

, where the bulk density was taken as the theorical density of $\mathrm{SiO}_{2}$-quartz $\left(2648 \mathrm{~kg} \cdot \mathrm{m}^{-3}\right)$, constituting $99.1 \%$ of the sand used in the printer.

Lost-on-ignitions (LOI) tests were finally performed on smalls cube of $10 \mathrm{~mm}$ side printed with the same parameters than the studied bars and cylinders. Measurements were provided by weighting the specimens before and after LOI tests performed at $1273 \mathrm{~K}$ in a furnace.

\section{Statistically Designed Experiments}

The permeability, strength, and density values of the printed specimens were implemented into a statistical model in order to quantify the process parameter effects. A two-level four-parameter factorial analysis is a good approach to scientifically establish the individual and combined effects of the two-level factors on the responses. The experiments were designed and carried out using six responses influenced by four factors, i.e. four process parameters. The six response variables were the permeabilities along $\mathrm{X}, \mathrm{Y}$, and $\mathrm{Z}$, the strength of bars printed along $\mathrm{X}$ and $\mathrm{Y}$ directions, and the

\footnotetext{
${ }^{\dagger}$ Simpson ${ }^{\circledR}$ Technologies brand

+ Simpson ${ }^{\circledR}$ Technologies brand

$\$ \$$ This is not the standared gas permeability definition according to Darcy law and hence does not have the SI unit of gas permeability but is used in the foundry industries, recomended by AFS.
} 
density of the printed specimens. No bars along the Z-direction were printed to limit the height and the cost of each printed job-box.

The factors were the position $\mathrm{X}$ and $\mathrm{Y}$ in the job box, the recoater speed (RS), and print resolution $\left(\mathrm{X}_{\mathrm{R}}\right)$. Only the mold samples at the job box corners were used for the statistical experiments. The factors were selected to form a two-level L16 orthogonal array experiment (Table 3). The parameter levels were chosen after a preliminary research in order to expect a linear relationship between the responses and the experiment variables. The most influencial factors were selected to model the printing process. The effect of the selected process parameters on the responses were calculated using a statistical approach. The standard error of the responses and the additional measurements to validate the models were quantified by printing several job-boxes with the parameters of $120 \mu \mathrm{m}\left(\mathrm{X}_{\mathrm{R}}\right)$ and 234 $\mathrm{mm} \cdot \mathrm{s}^{-1}(\mathrm{RS})$.

Table 3: Process parameters with their ranges and values at two levels.

\begin{tabular}{|c|c|c|c|c|}
\hline Parameter Designation & Process Parameter & Range & Level 1 & Level 2 \\
\hline $\mathrm{X}$ & X-position in job box $(\mathrm{mm})$ & $50-750$ & 50 & 750 \\
\hline $\mathrm{Y}$ & Y-position in job box $(\mathrm{mm})$ & $50-450$ & 50 & 450 \\
\hline $\mathrm{X}_{\mathrm{R}}$ & Print Resolution $(\mu \mathrm{m})$ & $120-140$ & 120 & 140 \\
\hline $\mathrm{RS}$ & Recoater Speed $\left(\mathrm{mm} \cdot \mathrm{s}^{-1}\right)$ & $130-286$ & 130 & 286 \\
\hline
\end{tabular}




\section{RESULTS}

\section{Repeatability}

Job-boxes with the parameters of $120 \mu \mathrm{m}\left(\mathrm{X}_{\mathrm{R}}\right)$ and $234 \mathrm{~mm} \cdot \mathrm{s}^{-1}(\mathrm{RS})$, which were within the factorial analysis range, were printed to evaluate the repeatability of the measurements and the residual errors of the models. The repeatabilities in the measurements were $\pm 10 \mathrm{~kg} \cdot \mathrm{m}^{-3}$ (density), $\pm 4 \mathrm{GP}$ (permeability), and $\pm 0.10 \mathrm{MPa}$ (3PB strength). These values served as a benchmark to identify the influential parameters during the statistically designed experiments.

\section{Process Parameters Effects}

The measured values of the responses, i.e. permeabilities $\left(P_{X}, P_{Y}\right.$, and $\left.P_{Z}\right)$, flexural strength $\left(\sigma_{X}\right.$ and $\left.\sigma_{Y}\right)$, and density $(\rho)$, were used to build the mathematical models for the $3 \mathrm{D}$ printer ${ }^{* * *}$ characterization and are summurized in the Appendix. The linear regression analysis for each response when considering up to the $1^{\text {st }}$ order combined effects were summarized in Table 4 . Residual errors were calculated by ignoring the $2^{\text {nd }}$ to $4^{\text {th }}$ order combined effects. Applying the mathematical model with the coefficients listed in Table 3 to the initial printing conditions lead to maximum residual errors of $\pm 9 \mathrm{GP}, \pm 0.11 \mathrm{MPa}$, and $\pm 8 \mathrm{~kg} \cdot \mathrm{m}^{-3}$ for permeability, flexural strength, and density, respectively.

Table 4 : Coefficients of process parameter effects on permeability, flexural stress, and density.

\begin{tabular}{|c|c|c|c|c|c|c|c|}
\hline Parameters & Identifiers & $\begin{array}{c}\boldsymbol{P}_{X} \\
\left(\mathbf{G P} \mathbf{P}^{\dagger \dagger}\right)\end{array}$ & $\begin{array}{c}P_{Y} \\
(\mathbf{G P})\end{array}$ & $\begin{array}{c}P_{Z} \\
(\mathbf{G P})\end{array}$ & $\begin{array}{c}\sigma_{X} \\
(\mathbf{M P a})\end{array}$ & $\begin{array}{c}\sigma_{y} \\
\text { (MPa) }\end{array}$ & $\begin{array}{c}\rho \\
\left(\mathrm{kg} \cdot \mathrm{m}^{-3}\right)\end{array}$ \\
\hline Average & $\mathrm{M}$ & 115.6 & 97.1 & 98.6 & 1.913 & 1.969 & 1311 \\
\hline$X$ & A & -10.3 & -9.8 & -10.4 & 0.119 & 0.106 & 22 \\
\hline $\mathrm{Y}$ & $\mathrm{B}$ & -2.8 & -1.1 & -3.2 & 0.157 & 0.069 & 3 \\
\hline $\mathrm{X}_{\mathrm{R}}$ & $\mathrm{C}$ & 0.8 & 0.5 & -0.9 & -0.206 & -0.238 & -2 \\
\hline $\mathrm{RS}$ & $\mathrm{D}$ & 19.9 & 15 & 19.8 & -0.325 & -0.406 & -4.8 \\
\hline $\mathrm{X}-\mathrm{Y}$ & $\mathrm{AB}$ & 0.6 & 2.3 & 0.8 & 0.038 & 0.043 & 3 \\
\hline$X-X_{R}$ & $\mathrm{AC}$ & -3.3 & -3.8 & -1.2 & -0.013 & 0.025 & 3 \\
\hline X-RS & $\mathrm{AD}$ & -5.9 & -4.6 & -5.9 & 0.056 & 0.056 & 9 \\
\hline$Y-X_{R}$ & $\mathrm{BC}$ & -0.1 & 0 & -0.4 & -0.075 & -0.013 & -3 \\
\hline Y-RS & $\mathrm{BD}$ & -1.9 & -2.5 & -3.6 & 0.069 & 0.006 & 3 \\
\hline $\mathrm{X}_{\mathrm{R}}-\mathrm{RS}$ & $\mathrm{CD}$ & -1.3 & -2.3 & -2.9 & 0.069 & 0.038 & 6 \\
\hline \multicolumn{2}{|c|}{ Maximum residual errors } & 6 & 9 & 4 & 0.11 & 0.09 & 8 \\
\hline \multicolumn{2}{|c|}{ Minimum } & 89.7 & 72.3 & 71.7 & 1.175 & 1.156 & 1226 \\
\hline \multicolumn{2}{|c|}{ Maximum } & 159.9 & 134.4 & 144.7 & 2.788 & 2.794 & 1383 \\
\hline
\end{tabular}

\footnotetext{
*** ExOne's S-Print ${ }^{\mathbf{T M}}$

$\dagger$ Commonly used AFS number for gas permeability of sand mold, but does not have the SI or proper scientific unit.
} 
The most effective factors affecting the printed sample characteristics were the job box positions $\mathrm{X}$ and $\mathrm{Y}$, and the recoater speed RS. They are believed to impact the density which is a key factor for the permeability and strength. Nevertheless, the $X_{R}$ parameter significantly affected only the strength of mold samples.

While permeability is primarly influenced by the sand grain size and shape, the sand compaction, and the amount of binder [15], this study revealed that the effect of the binder amount was negligeable in regards to the sand compaction. This may be due to the fact that the binder quantity was varying from approximately 1.9 to $2.2 \mathrm{wt}$ \% (according to LOI tests), which may be too small to effectively affect the number of inter-grain cavities filled by the binder. Therefore, the impact of binder amount on permeability was within the noise of the permeability measurements.

\section{Sand Mold Properties}

Sand mold properties (Table 3) varied within the factorial analysis parameters with a wide range of 70 to $160 \mathrm{GP}$ and 1.1 to $2.8 \mathrm{MPa}$. The density varied from 1226 to $1383 \mathrm{~kg} \cdot \mathrm{m}^{-3}$, which represented a porosity variation from 48 to $54 \%$.

The average value of sample densities of $1331 \mathrm{~kg} \cdot \mathrm{m}^{-3}$ agreed with another study [12]. The sand compaction was mainly controlled by the RS parameter and the position in the jobbox. The observed heterogeneous compaction of sand grains within a single job box agreed with another work [30]. The effect of $X_{R}$ parameter (value of -2) was negligeable. Even though the density of the furfuryl alcohol $\left(1130 \mathrm{~kg} \cdot \mathrm{m}^{-3}\right)$ was not negligeable, its small variation in quantity did not play a significant role in the total weight of the samples. Indeed, lost-on-ignition measurements performed at $1273 \mathrm{~K}$ revealed a furan content variation from $1.9 \mathrm{wt} . \%\left(\mathrm{X}_{\mathrm{R}}=140 \mu \mathrm{m}\right)$ to $2.3 \mathrm{wt} . \%\left(\mathrm{X}_{\mathrm{R}}=120 \mu \mathrm{m}\right)$, slightly higher than LOI measurements of other studies [5,33]. Such variation corresponded to a variation of $\pm 0.002 \mathrm{wt} . \%$, in agreement with the -2 value of the $\mathrm{X}_{\mathrm{R}}$ parameter for density modeling.

The model for permeabilities had numerous similitudes with the density model, that were strong $X$ and RS parameters, smaller $Y$ parameter, and negligeable $X_{R}$ parameter. A strong correlation between density and permeability was observed (Fig. 4) with a linear dependance of permeability with density and a saturation of the permeabilities above $1360 \mathrm{~kg} \cdot \mathrm{m}^{-3}$. Fitting the data lead to Eq. 3 :

$$
P=-0.429 \cdot \rho+D \quad\left(\mathrm{R}^{2}=0.83\right) \quad(\text { Eq.3 })
$$


, where $D$ is a constant that equals 678 for $P_{X}$ and 661 for $P_{Y}$ and $P_{Z}$. The offset of 17 GP between the $P_{X}$ values on one side and the $P_{Y}$ and $P_{Z}$ values on the other side remains unclear. The favorable air flow along $\mathrm{X}$ than $\mathrm{Y}$ and $\mathrm{Z}$ was surprising. We would have expected a different $\mathrm{Z}$ permeability because of the layer-by-layer deposition (X-Y plane) manufacturing mode. This is believed to be due to the compaction that is performed by an oscillating blade located beneath the recoater. The sand compaction could vary in the $\mathrm{Y}$ recoating direction according to the sandwave distributed ahead of the oscillating compacting blade. The pressure exerted along $\mathrm{Y}$ and $\mathrm{Z}$ should organize the grains in such a heterogeneous way that porosities were more oriented along the $\mathrm{X}$ direction, leading to anisotropic permeability.

The mold flexural strength did not depend significantly on the printing direction (X or $\mathrm{Y}$ ) in the deposition plane and was greater for high compaction (obtained by small RS values in the 130-182 $\mathrm{mm} \cdot \mathrm{s}^{-1}$ range), high furan amount (abtained at small $\mathrm{X}_{\mathrm{R}}$ values of $120 \mu \mathrm{m}$ ), and towards the $\mathrm{X}_{0} \mathrm{Y}_{0}$ corner. Slowing the recoater speed increased the sand density inducing greater flexural strength, in agreement with other works [12]. The flexural strength values varied from 1.12 to 2.76 MPa with standard deviation up to $0.24 \mathrm{MPa}$, in agreement with other publications on ExOne S-Print ${ }^{\mathrm{TM}}[5]$ and ZCorp printer [9] and greater than traditional furan sand mold samples [33]. Strength heterogeneity in the job box was in agreement with another studies [26,34] and was associated to the sand density variation, as highlighted by Fig 5 and Eq. 4:

$$
\sigma=0.743 \cdot \rho-781.1\left(\mathrm{R}^{2}=0.72\right) \quad(\text { Eq. } 4)
$$

The standard deviation around this linear trend was $\pm 0.25 \mathrm{MPa}$. This was due to the $\mathrm{X}_{\mathrm{R}}$ effect, not included in the present graph. Indeed, the $\pm 0.25 \mathrm{MPa}$ was very close to the $\mathrm{X}_{\mathrm{R}}$ effect for stress models, that is -0.206 and $-0.238 \mathrm{MPa}$ for $\sigma_{\mathrm{x}}$ and $\sigma_{\mathrm{z}}$, respectively. However, the effect of a Y-parameter was not clear. Such a dependence of the strength with the binder deposition axis has been related in other works to a preferential spreading of the binder towards the printhead movement direction due to the impact trajectory of the droplet [34,35]. This may not be the case in the present work because the impact trajectory of the droplet is composed of a fast $\mathrm{Y}$-velocity component (Y-direction printhead movement). Therefore, it is believed that the $\mathrm{Y}$-variation of the printed sample stress may be related to the binder preferential spreading on a less compacted sand (towards $\mathrm{Y}_{500}$ positions).

Finally, a strong correlation existed between the flexural stress and permeability, as indicated in Fig. 6 . The relationship was given by :

$$
P=-0.43 \cdot \sigma+189.6 \quad\left(\mathrm{R}^{2}=0.53\right)
$$


Albeit a small coefficient of determination, the trend given by Eq. 7 was valid up to $2.4 \mathrm{MPa}$ flexural stresses, after which permeability remains unchanged at 95 and 76 GP along X and Y, respectively. This was directly due to the saturation effect observed in Fig. 3.

\section{Heterogeneity of Properties}

The sample properties depended upon their position in the job box, in agreement with previous works $[11,24,36]$. The heterogeneity in a job box was quantified by analyzing statistically the measured properties of the printed specimens in each job box (Fig. 2). The equations for the standard deviation of permeability $\left(S_{P}\right)$, flextural strength $\left(S_{\sigma}\right)$ and density $\left(S_{\rho}\right)$ were given by:

$$
\begin{aligned}
& S_{p}=10.6+1.8 F D S+4.7 R S+2.64(F D S-R S) \\
& S_{\sigma}=0.203+0.003 F D S+0.021 R S+0.021(F D S-R S) \\
& S_{\rho}=23.8+2.8 F D S+9.3 R S+8.3(F D S-R S)
\end{aligned}
$$

The homogeneity in properties in the same job box was strongly affected by the RS parameter, meaning that slow recoater speeds, i.e. slow sand layer deposition, enabled the manufacturing of a job box with homogeneous sample characteristics. The measured sand specimen properties were most homogeneous in the Y-building direction rather than the X-direction, the reason being possibly related to the observed RS-X combined effect induced by the printer design. Indeed, the sand compaction depended on the $\mathrm{X}$ position in the job-box, the recoater speed, and the interaction of these two parameters. The sand was deposited by a recoater movement from $Y_{500}$ to $Y_{0}$. The screw conveyor in the recoater transported the sand from the sand container $\left(\mathrm{X}_{800}\right)$ to the recoater extremity $\left(\mathrm{X}_{0}\right)$. This $\mathrm{X}$ dependence upon sand compaction cannot be related to the distribution of the sand by the screw conveyor as the sand height in the conveyor was continuously controlled and maintained constant. Therefore the outwards sand flow variations along the X-direction was believed to be due to a variation of the front-blade spacing of the conveyor. Therefore, the present results justified a slight modification in the front-blade spacing adjustment by enlarging this spacing near the $\mathrm{X}_{0}$ position to increase the local flow of the sand deposition.

\section{DISCUSSION}

Printing sand molds using the ExOne's S-Print ${ }^{\mathrm{TM}}$ was performed in order to validate permeability and strength requirements. A minimum nominal strength is required for an easy manipulation of the mold and good dimensional accuracy of the casting. This rigidity should be obtained with a minimum 
binder resolution $\left(X_{R}=140 \mu \mathrm{m}\right)$, that means small Loss-On-Ignition values, to reduce the off-gassing that hinders the filling of the sand mold cavity $[5,13,14,29]$.

The volume of gas evolved is proportional in part to the amount of binder present in the printed mold [28]. Sufficient permeability is necessary to allow the escape of gases produced when the molten metal heats the internal surface of the mold cavity. Therefore a balance must be found between strength and permeability as an increase of the sand density simultaneously increases the mold strength and reduced the mold permeability (Table 3) and was in agreement with another similar study [35].

Various 3D machine settings exist regarding print resolution, recoater speed, and mold position which will give optimised sand mold properties in terms of a particular permeability-strength combination. The algorithm for setting the printer parameter values is an iterative procedure that determines first if the permeability and strength requirements for the sand mold are simultaneously achievable, followed by a minimization of the furan content.

In the present work the aim is to obtain a minimum sand mold strength of $1.8 \mathrm{MPa}$ with the greatest permeability and smallest furan content. By fixing the $X_{R}$ parameter to $+1(140 \mu \mathrm{m})$, the lower flexural stress value of $1.80 \mathrm{MPa}$ in $\mathrm{X}_{0} \mathrm{Y}_{0}$ corner $(\mathrm{X}=\mathrm{Y}=-1)$ is reached for both $\mathrm{X}$ - and $\mathrm{Y}$-stresses at recoater speed values slower than $158 \mathrm{~mm} \cdot \mathrm{s}^{-1}$ (corresponding to $\mathrm{RS}=-0.64$ ).

Fixing $X_{R}$ and RS values to +1 and -0.64 , respectively, the sand mold sample properties in the job box are calculated (Table 5) and compared to measured properties in a job box printed in the same conditions (Table 6). The mathematical model fits approximatively the real sand mold properties. However, the residual error is greater for permeability and density, suggesting that the compaction effect is the main error in the model. This is believed to be due to a non-perfectly linear sand compaction magnitude in relation to the recoater speed. Therefore the authors suggest that, while $\mathrm{X}$, $\mathrm{Y}$, and $\mathrm{X}_{\mathrm{R}}$ parameters can be kept as two-level factors, the RS parameter must be studied at least as a three-level factor for future investigations.

Table 5 : Calculated mold sample properties for $X_{R}$ and RS values of $140 \mu \mathrm{m}$ and $158 \mathrm{~mm} \cdot \mathrm{s}^{-1}$ according to the model proposed in Table 3.

\begin{tabular}{|c|c|c|c|c|c|c|c|}
\hline $\mathbf{X}$ & $\mathbf{Y}$ & $\mathbf{P}_{\mathbf{X}}(\mathbf{G P})$ & $\mathbf{P}_{\mathbf{Y}}(\mathbf{G P})$ & $\mathbf{P}_{\mathbf{Z}}(\mathbf{G P})$ & $\boldsymbol{\sigma}_{\mathbf{X}}(\mathbf{M P a})$ & $\boldsymbol{\sigma}_{\mathbf{y}}(\mathbf{M P a})$ & $\begin{array}{c}\boldsymbol{\rho} \\
\left(\mathbf{k g} \cdot \mathbf{m}^{-\mathbf{3}}\right)\end{array}$ \\
\hline-1 & -1 & 115 & 101 & 96 & 1.81 & 1.87 & 1324 \\
\hline 1 & -1 & 95 & 76 & 79 & 1.87 & 1.98 & 1356 \\
\hline-1 & 1 & 111 & 100 & 92 & 1.81 & 1.89 & 1314 \\
\hline 1 & 1 & 93 & 81 & 78 & 2.02 & 2.16 & 1358 \\
\hline
\end{tabular}




\begin{tabular}{|c|c|c|c|}
\hline Average & 93.1 & 1.92 & 1338 \\
\hline $\begin{array}{c}\text { Standard } \\
\text { deviation }\end{array}$ & 12.8 & 0.12 & 22 \\
\hline
\end{tabular}

Table 6 : Measured mold sample properties for $X_{R}$ and RS values of $140 \mu \mathrm{m}$ and $158 \mathrm{~mm} \cdot \mathrm{s}^{-1}$

\begin{tabular}{|c|c|c|c|c|c|c|c|}
\hline $\mathbf{X}$ & $\mathbf{Y}$ & $\mathbf{P}_{X}(\mathbf{G P})$ & $P_{Y}(G P)$ & $\mathbf{P}_{\mathrm{Z}}$ (GP) & $\begin{array}{c}\sigma_{\mathbf{X}} \\
(\mathbf{M P a})\end{array}$ & $\begin{array}{c}\sigma_{\mathbf{y}} \\
(\mathbf{M P a})\end{array}$ & $\begin{array}{c}\rho \\
\left(\mathbf{k g} \cdot \mathbf{m}^{-3}\right)\end{array}$ \\
\hline-1 & -1 & 98 & 78 & 76 & 1.70 & 1.85 & 1341 \\
\hline 1 & -1 & 93 & 71 & 69 & 1.85 & 1.90 & 1382 \\
\hline-1 & 1 & 96 & 77 & 80 & 1.85 & 1.90 & 1338 \\
\hline 1 & 1 & 85 & 65 & 66 & 2.20 & 2.00 & 1385 \\
\hline \multicolumn{2}{|c|}{ Average } & \multicolumn{3}{|c|}{79.5} & \multicolumn{2}{|c|}{1.91} & 1362 \\
\hline \multicolumn{2}{|c|}{$\begin{array}{l}\text { Standard } \\
\text { deviation }\end{array}$} & \multicolumn{3}{|c|}{11.4} & \multicolumn{2}{|c|}{0.15} & 25 \\
\hline
\end{tabular}

\section{CONCLUSIONS}

The measured properties of the 3D printed furan sand molds were analyzed using the statistical design of experiments to identify the important factors. Mathematical models revealed that the mold properties were dependent upon the process parameters, such as recoater speed and print resolution, and their positions, within the job box, during printing. While the recoater speed influenced both strength and permeability, the print resolution only affected the mold strength at the current settings. An optimization procedure is proposed by setting the flexural stress of mold samples at $1.80 \mathrm{MPa}$ or above (an arbitrary value) with a minimum furan amount. The model proposed for the 3D printer was validated by measuring the properties of the sand specimens at the determined printing conditions. If small permeabilities are accepted for sand molds, slow recoater speeds can be used. However, if sand molds are manufactured with a high permeability using fast recoater speeds, it leads unfortunately to anisotropic properties of the sand specimens within a given job-box. Novel findings of this paper include in particular the quantification of the printing parameters effect on the characteristics of the sand mold specimens. Moreover, the machine model enables to calculate the different permeabilitystrength couples achievable by our ExOne S-Print ${ }^{\mathrm{TM}}$ machine.

Although the statistical analysis provides a best-fitting linear regression for strength and permeability of the printed sand specimens in relation to the 3D printer settings, what is of particular importance here is the ability to control them independently, up to a limit, to predict the permeability and strength properties. Nevertheless, the effect of the printing parameters on the casting properties needs to be investigated. Therefore future work will focus on the consequence of sand mold manufacturing conditions on the casting properties, as flexural strength and permeability values for the sand mold are 
achievable with different values of recoater speed and print resolution. In addition, the consideration of the Z-direction for flexural strength, which may be a weak direction, must be analyzed with future mold printings.

\section{ACKNOWLEDGEMENTS}

The authors acknowledge the help of the following colleagues at Arts et Métiers ParisTech. Thanks are due to J. Bourgeois for his technical support on 3D printing and $\mathrm{M}$. Pons for his advice on statistical designs.

\section{REFERENCES}

[1] Dimitrov D, Schreve K, de Beer N, Chritiane P. Three dimensional printing in the South African industrial environment. South African J ... 2008;19:195-213.

[2] Sachs E, Cima M, Cornie J, Brancazio D. Dimensional Printing: Rapid Tooling and Prototypes Directly from CAD Representation. Solid Free Fabr Symp 1990:27-47. doi:10.1016/S00078506(07)61035-X.

[3] Travitzky N, Bonet A, Dermeik B, Fey T, Filbert-Demut I, Schlier L, et al. Additive manufacturing of ceramic-based materials. Adv Eng Mater 2014;16:729-54. doi:10.1002/adem.201400097.

[4] Singamneni S, Diegel O. Some recent developments and experiences with Rapid Manufacturing by indirect means. Asian Int J Sci Technol Prod Manuf Eng 2010;3:7-14

[5] Snelling D, Williams CB, Druschitz AP. A Comparison of Binder Burnout and Mechanical Characteristics of Printed and Chemically Bonded Sand Molds. SFF Symp 2014:197-209.

[6] Stefanic I, Raos P, Samardzic I, Tintor B, Musser E. Rapid Prototyping of Casting Cores. Teh Vjesn Gaz 2012;19:459-64.

[7] Budzik G. Possibilities of utilizing 3DP technology for foundry mould making. Arch Foundry Eng 2007;7:65-8.

[8] Drokina V V., Belov VD, Chekhonin SN. Obtaining casts of aluminum alloys by foundry in 
[9] Koltygin A V., Bazhenov VE. Development of a Substitute for Z Cast Molding Sand Used on Installations of 3D Printing for Obtaining Aluminum, Magnesium, and Iron Casting. Russ $\mathbf{J}$ Non-Ferrous Met 2012;53:38-41. doi:10.3103/S1067821212010129.

[10] Kumar R, Ahuja IPS, Singh R. Experimental and Analytical Analysis of Light Alloy Shell Castings Using Three Dimensional Printing 2014;2:650-62.

[11] Gill SS, Kaplas M. Efficacy of powder-based three-dimensional printing (3DP) technologies for rapid casting of light alloys. Int J Adv Manuf Technol 2011;52:53-64.

[12] Bobby SS. A PRELIMINARY INVESTIGATION OF GYPSUM BONDED MOULDS BY THREE DIMENSIONAL PRINTING 2014:501-7.

[13] Hościło B, Kaczyński R, Skorulski G. Rapid Prototyping Technology Using for Casting Process of Mini Turbine Runner. Arch Foundry Eng 2014;14:83-6.

[14] Snelling D, Li Q, Meisel N, Williams CB, Batra RC, Druschitz AP. Lightweight metal cellular structures fabricated via 3D printing of sand cast molds. Adv Eng Mater 2015;17:923-32. doi:10.1002/adem.201400524.

[15] Mckenna N, Singamneni S, Diegel O, Singh D, Neitzert T, George JS, et al. Direct Metal casting through 3D printing: A critical analysis of the mould characteristics. 9th Glob Congr Manuf Manag 2008:12-4.

[16] Motoyama Y, Inoue Y, Saito G, Yoshida M. A verification of the thermal stress analysis, including the furan sand mold, used to predict the thermal stress in castings. J Mater Process Technol 2013;213:2270-7. doi:10.1016/j.jmatprotec.2013.06.024.

[17] Motoyama Y, Takahashi H, Inoue Y, Shinji K, Yoshida M. Dymanic Measurements of the Load on Castings and the Contraction of Castings During Cooling in Sand Molds. J Mater Process Technol 2013;213:238-44.

[18] Nyembwe K, de Beer DJ, van der Walt JG, Bhero S. Assessment of Surface Finish and Dimensional Accuracy of Tools. South African J Ind Eng 2012;23:130-43.

[19] Singh R. Three Dimensional Printing for Casting Applications: A State of Art Review and Future Perspectives. Adv Mater Res 2009;83-86:342-9. doi:10.4028/www.scientific.net/AMR.83-86.342.

[20] Ollison T, Berisso K. Three-Dimensional Printing Build Variables That Impact Cylindricity. J 
Ind Technol 2010;26:1-10.

[21] Lee S-JJ, Sachs E, Cima M. Layer position accuracy in powder-based rapid prototyping. Rapid Prototyp J 1995;1:24-37. doi:10.1108/13552549510104447.

[22] Lee S-JJ, Sachs E, Cima M. Powder layer position accuracy in powder-based rapid prototyping. Best Available 1993:223.

[23] Brabazon D, Kennedy D, Tyrell M. Development of technique for 3D printed mould intricate rapid casting. Solid Free. Fabr. Symp., 2010, p. 800-8.

[24] Dimitrov D, Beer N De. Developing Capability Profile for the Three Dimensional Printing Process. R D J 2006;22:17-25.

[25] Snelling D, Blount H, Forman C, Ramsburg K, Wentzel A, Williams C, et al. The effects of 3D pritned molds on metal castings. Solid Free Fabr Symp 2013:827-45.

[26] Frascati J. Effects of position, orientation, and infiltrating material on three-dimensional printing models. 2007.

[27] Vaezi M, Chua CK. Effects of layer thickness and binder saturation level parameters on 3D printing process. Int J Adv Manuf Technol 2011;53:275-84. doi:10.1007/s00170-010-2821-1.

[28] Castings n.d.

[29] Meisel N a., Williams CB, Druschitz A. Lightweight Metal Cellular Structures via Indirect 3D Printing and Casting. Solid Free. Fabr. Symp., 2012, p. 162-76.

[30] Budding A, Vaneker THJ. New strategies for powder compaction in powder-based rapid prototyping techniques. Procedia CIRP 2013;6:527-32. doi:10.1016/j.procir.2013.03.100.

[31] Renhe H, Hongmei G, Yaoji T, Qingyun L. Curing mechanism of furan resin modified with different agents and their thermal strength. China Foundry 2011;8:161-5.

[32] Sivarupan T, Mansori MEL, Coniglio N. 3D Printing Process Parameters and Properties of Additively Manufactured Sand Mold for Rapid Casting: Strength and Permeability. Addit Manuf 2017.

[33] Hussein NIS, Ayof MN, Sokri NIM, Engineering M. Mechanical Properties and Loss on Ignition of Phenolic and Furan Resin Bonded Sand Casting 2013;1:1-5.

[34] Galeta T, Kladarić I, Karakašić M. Influence of Processing Factors on Tensile Strength of 3D Printed Models. Strojarstvo 2011;47:781-8.

[35] Farzadi A, Waran V, Solati-Hashjin M, Rahman ZAA, Asadi M, Osman NAA. Effect of layer 
printing delay on mechanical properties and dimensional accuracy of 3D printed porous prototypes in bone tissue engineering. Ceram Int 2015;41:8320-30. doi:10.1016/j.ceramint.2015.03.004.

[36] Szucs TD, Brabazon D. Analysis of the effects of 3DP parameters on part feature dimensional accuracy. Solid Free. Fabr. Symp. Proc., 2007, p. 470-81.

\section{APPENDIX}

Table A.1 : Average values of permeability, flexural stress, and density for various process parameters.

\begin{tabular}{|c|c|c|c|c|c|c|c|c|c|}
\hline \multicolumn{4}{|c|}{ Level of Process Parameters } & \multirow{2}{*}{$\begin{array}{c}P_{X} \\
(\mathbf{G P})\end{array}$} & \multirow{2}{*}{$\begin{array}{c}P_{Y} \\
(\mathbf{G P})\end{array}$} & \multirow{2}{*}{$\begin{array}{c}P_{Z} \\
(\mathbf{G P})\end{array}$} & \multirow{2}{*}{$\begin{array}{c}\sigma_{X} \\
(\mathbf{M P a})\end{array}$} & \multirow{2}{*}{$\begin{array}{c}\sigma_{y} \\
(\mathbf{M P a})\end{array}$} & \multirow{2}{*}{$\begin{array}{c}\rho \\
\left(\mathrm{kg} \cdot \mathrm{m}^{-3}\right)\end{array}$} \\
\hline$x$ & $\mathbf{Y}$ & $\mathbf{X}_{\mathbf{R}}$ & RS & & & & & & \\
\hline-1 & -1 & -1 & -1 & 95.94 & 81.38 & 79.94 & 2.31 & 2.59 & 1358 \\
\hline 1 & -1 & -1 & -1 & 92.69 & 74.38 & 71.69 & 2.39 & 2.56 & 1370 \\
\hline-1 & 1 & -1 & -1 & 93.19 & 79.63 & 80.19 & 2.56 & 2.66 & 1358 \\
\hline 1 & 1 & -1 & -1 & 92.19 & 81.63 & 75.19 & 2.79 & 2.79 & 1383 \\
\hline-1 & -1 & 1 & -1 & 106.94 & 94.88 & 87.19 & 1.94 & 2.02 & 1343 \\
\hline 1 & -1 & 1 & -1 & 90.44 & 72.38 & 74.19 & 1.96 & 2.08 & 1368 \\
\hline-1 & 1 & 1 & -1 & 103.94 & 93.13 & 85.69 & 1.89 & 2.03 & 1330 \\
\hline 1 & 1 & 1 & -1 & 89.69 & 79.63 & 75.94 & 2.06 & 2.27 & 1368 \\
\hline-1 & -1 & -1 & 1 & 154.19 & 130.38 & 144.69 & 1.28 & 1.58 & 1225 \\
\hline 1 & -1 & -1 & 1 & 127.19 & 104.88 & 112.69 & 1.58 & 1.77 & 1275 \\
\hline-1 & 1 & -1 & 1 & 143.69 & 118.63 & 130.19 & 1.80 & 1.67 & 1238 \\
\hline 1 & 1 & -1 & 1 & 118.94 & 102.13 & 101.44 & 2.25 & 2.03 & 1300 \\
\hline-1 & -1 & 1 & 1 & 159.94 & 134.38 & 140.19 & 1.18 & 1.16 & 1233 \\
\hline 1 & -1 & 1 & 1 & 119.69 & 93.38 & 103.44 & 1.43 & 1.44 & 1295 \\
\hline-1 & 1 & 1 & 1 & 149.19 & 122.63 & 123.94 & 1.40 & 1.19 & 1233 \\
\hline 1 & 1 & 1 & 1 & 111.19 & 90.63 & 90.44 & 1.80 & 1.66 & 1308 \\
\hline
\end{tabular}




\section{LIST OF FIGURES}

Fig. 1: Overview of 3D sand mold printer.

Fig.2: Top view of the job-box design.

Fig. 3: Schematic of (a) the direction of permeability test on the $X, Y$ and $Z$ cylindrical specimens and (b) the 3PB test specimen. [32].

Fig. 4: Relationship between density and permeability for x-, y-, and z- oriented specimens.

Fig. 5: Relationship between density and 3PB strength for $\mathrm{x}-, \mathrm{y}-$, and $\mathrm{z}-$ - oriented specimens.

Fig. 6: Relationship between $3 \mathrm{~PB}$ strength and permeability for $\mathrm{x}$ - and $\mathrm{y}$-orinted specimens. 


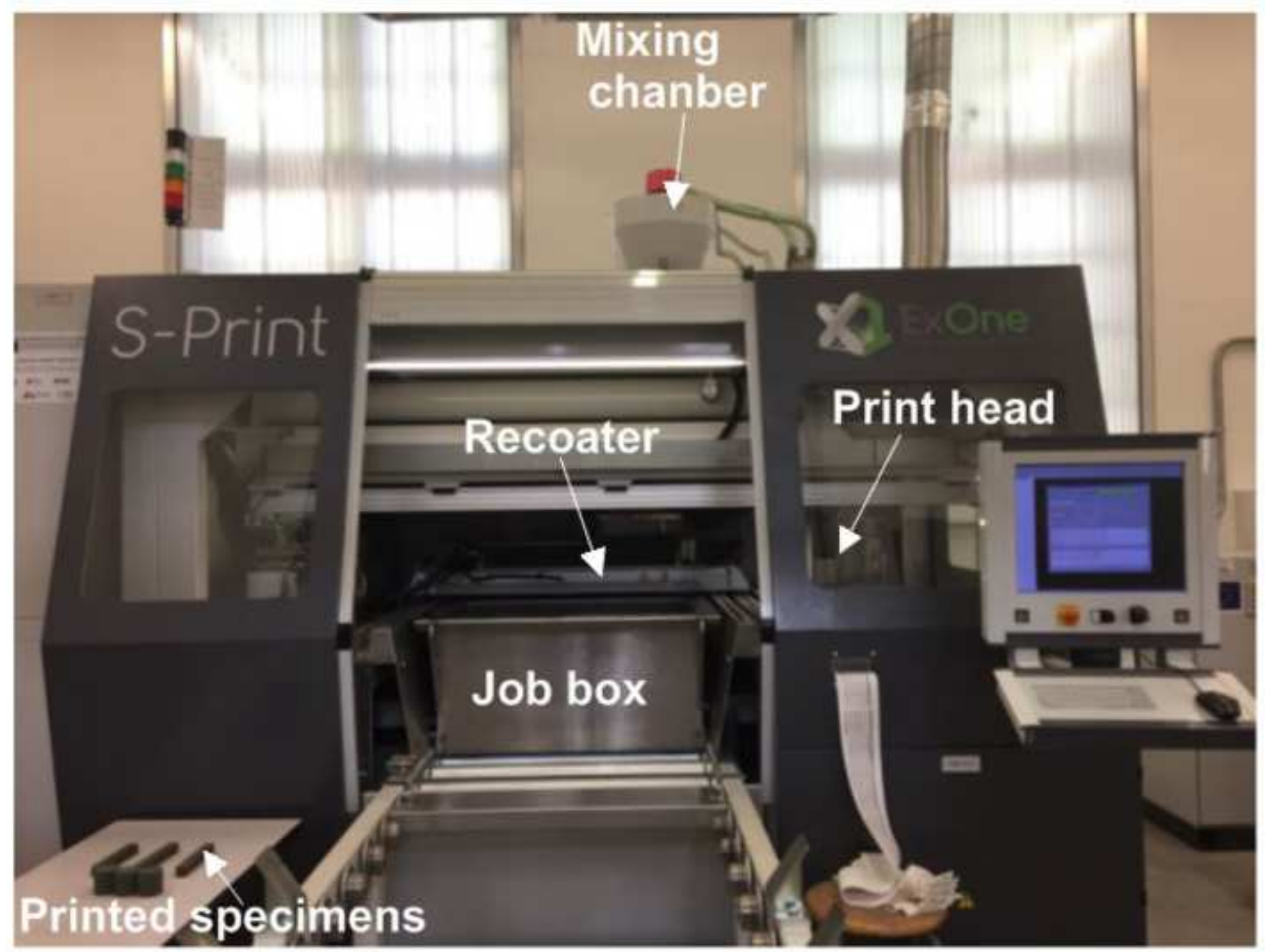



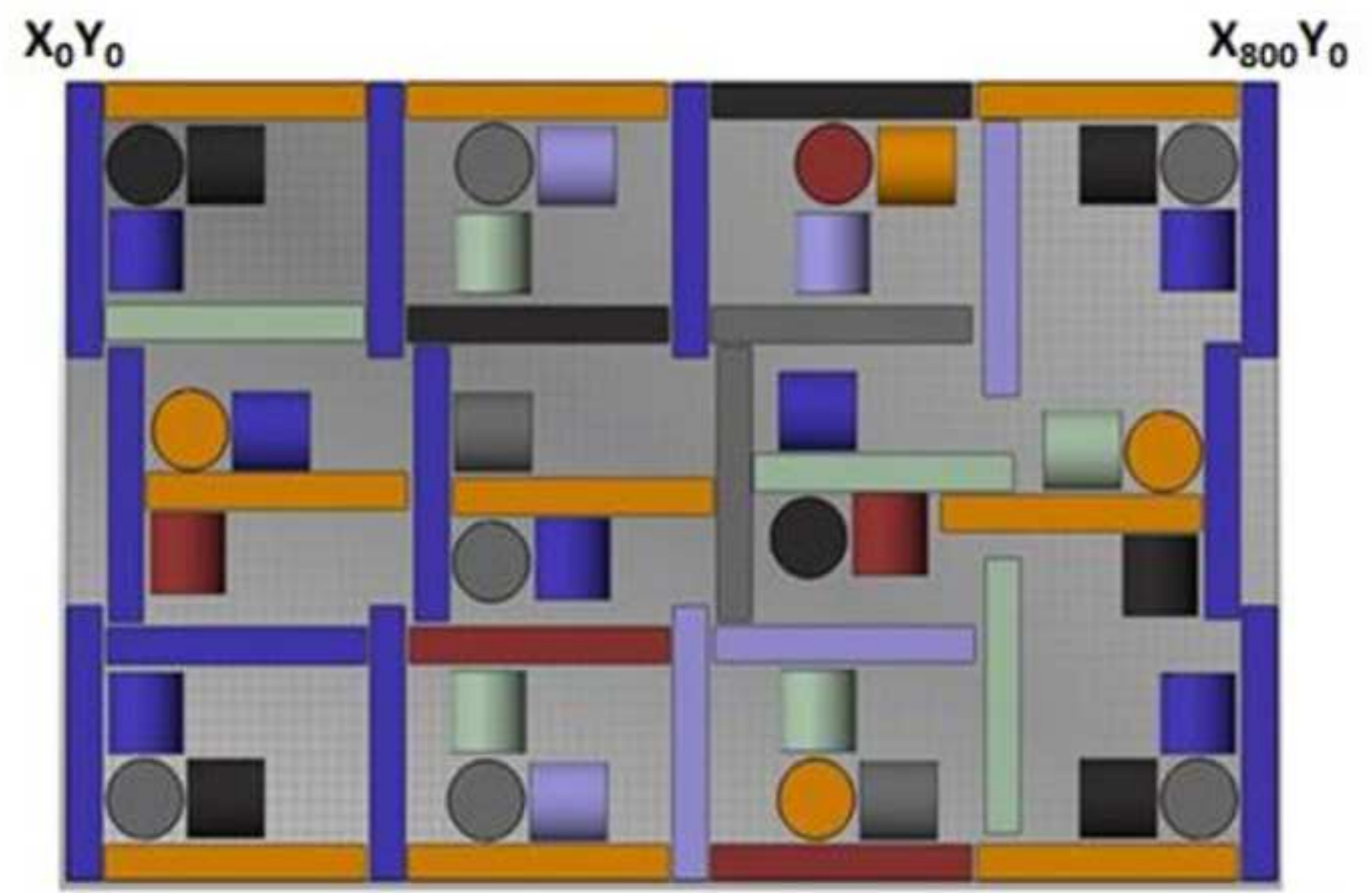

$X_{0} Y_{500}$

$X_{800} Y_{500}$ 


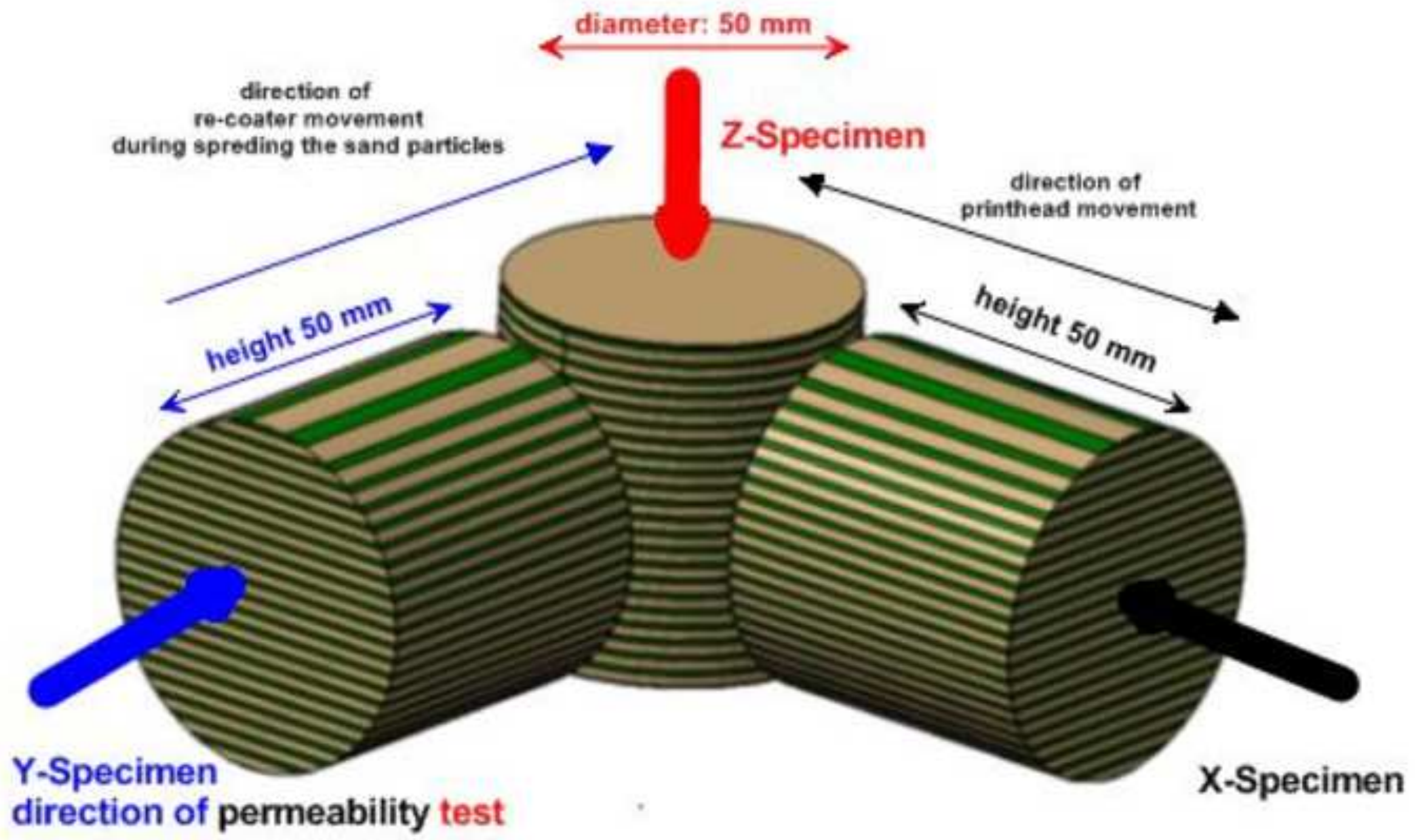
direction of permeability test 


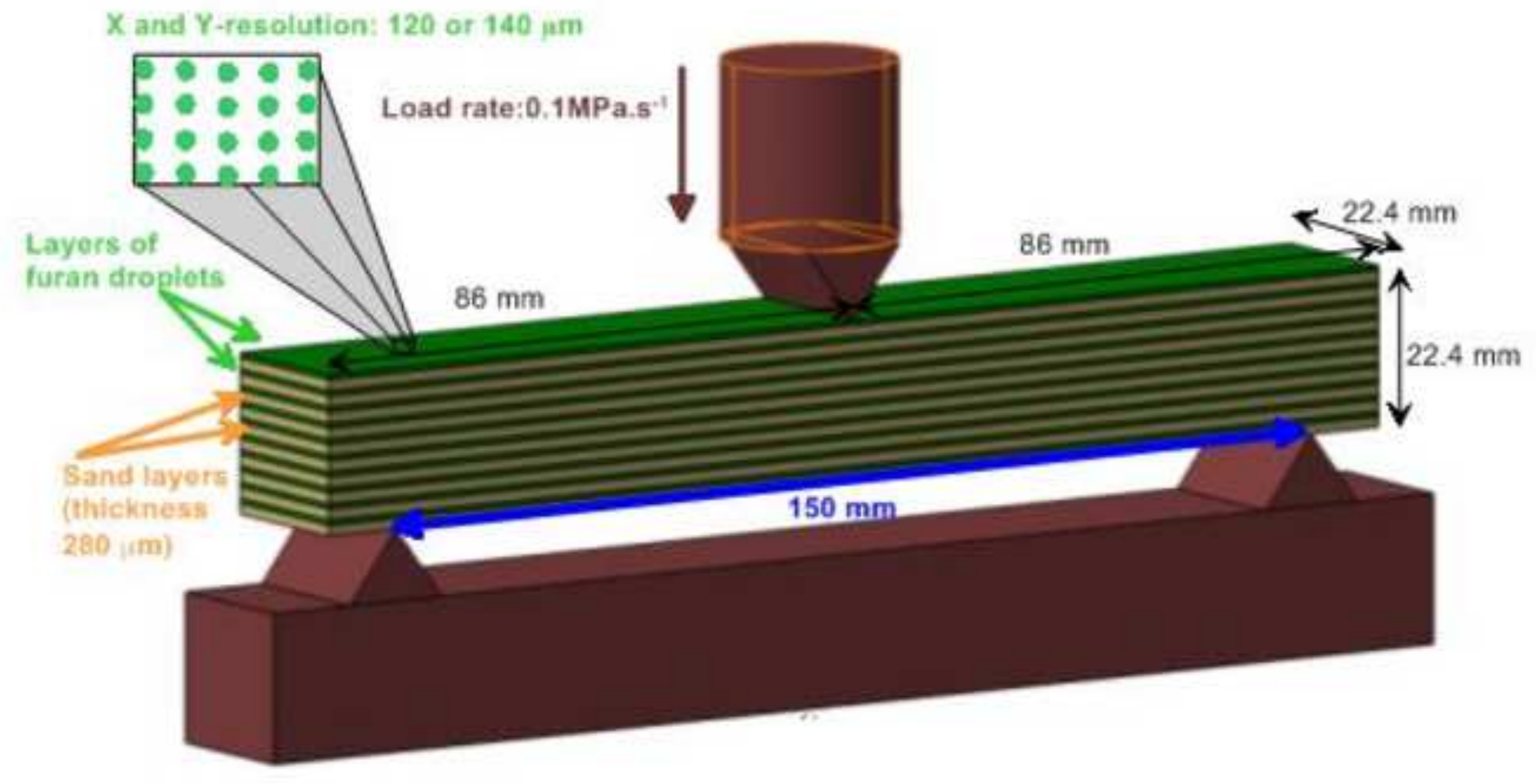

$X$ and $Y$-resolution: 120 or $140 \mu \mathrm{m}$

(thickness

$280 \mathrm{im}$
$150 \mathrm{~mm}$ 


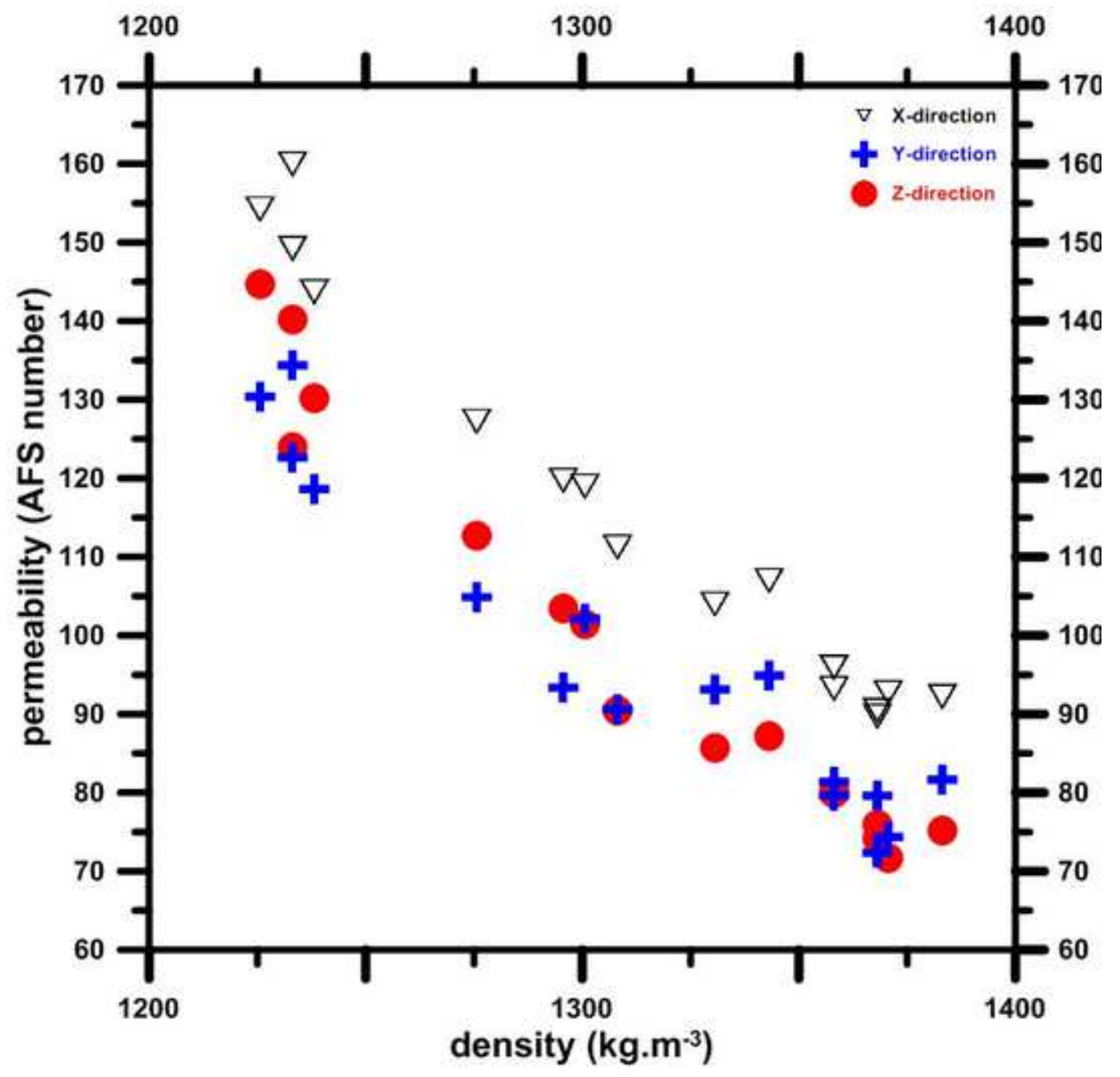




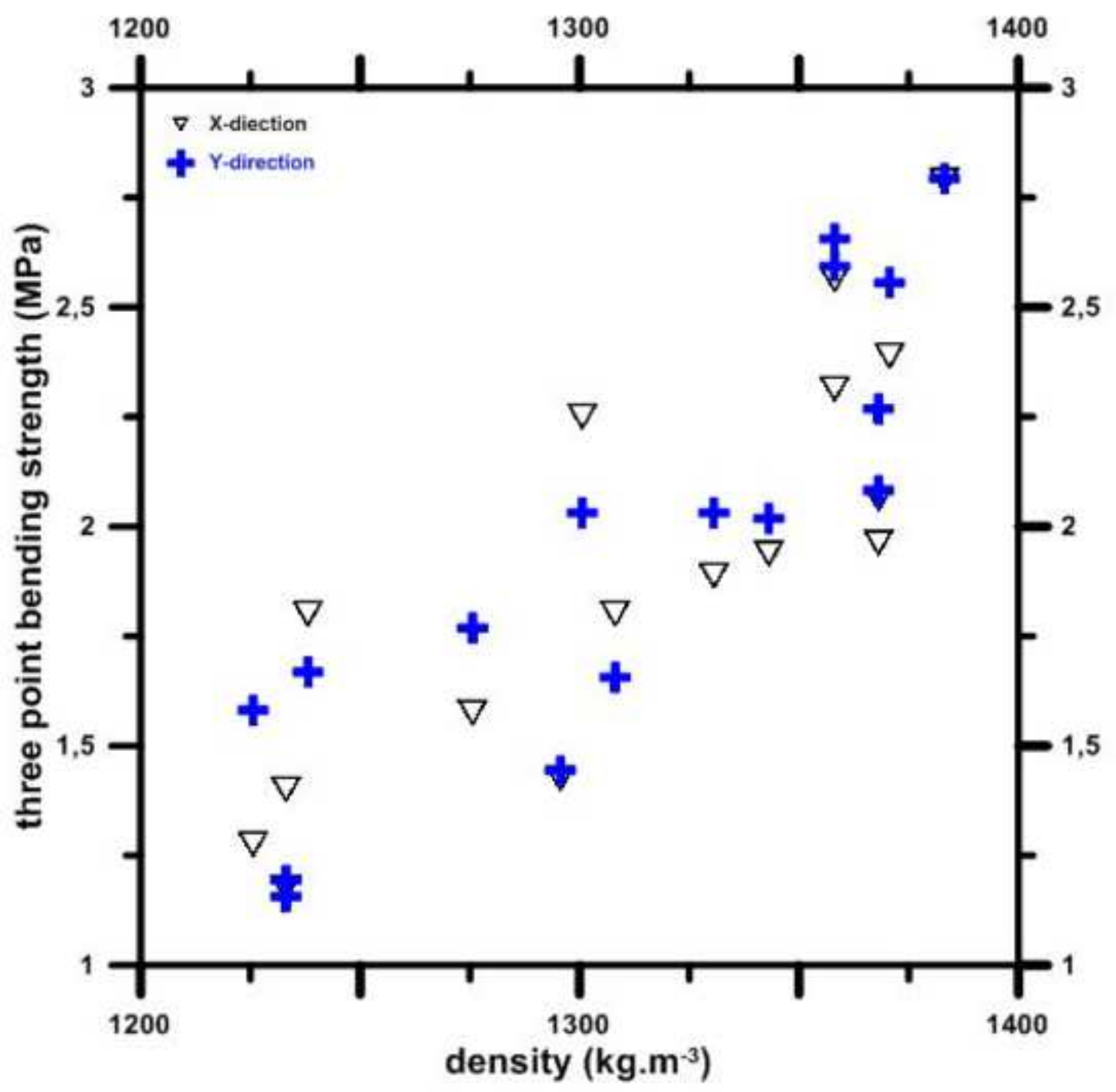




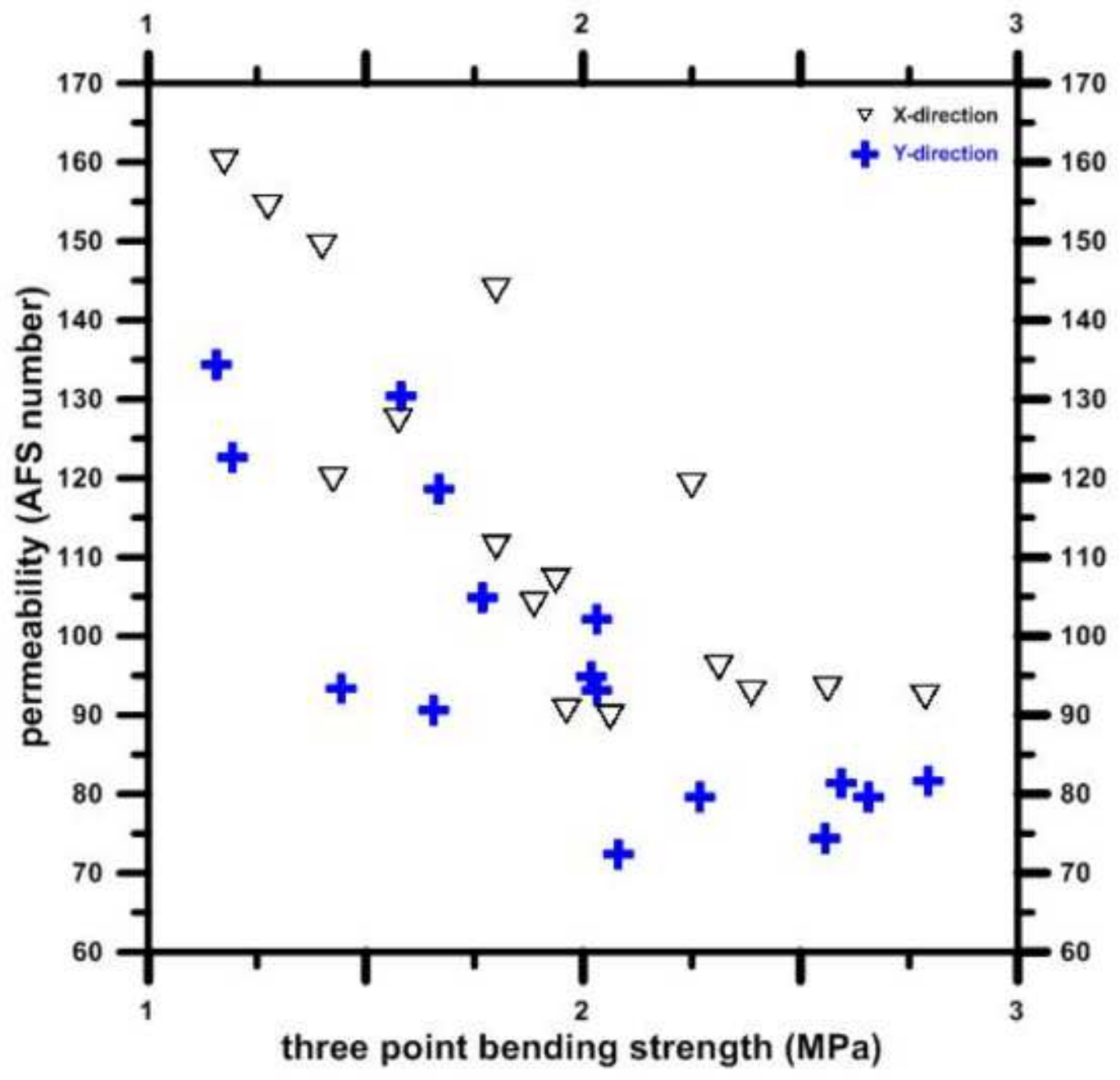




\section{List of Tables}

Table 1 : Dimensions, quantity, and orientations of specimens printed in each job box.

\begin{tabular}{|c|c|c|c|}
\hline Specimen & Dimensions (mm) & Direction & Number \\
\hline \multirow{2}{*}{$\begin{array}{c}\text { Bar } \\
\text { (for 3PB test) }\end{array}$} & \multirow{2}{*}{$22.4 \times 22.4 \times 172$} & $\mathrm{X}$ & 18 \\
\hline & & $\mathrm{Y}$ & 14 \\
\hline \multirow{3}{*}{$\begin{array}{c}\text { Cylinder } \\
\text { (for permeability test) }\end{array}$} & \multirow{3}{*}{$\begin{array}{c}\text { Diameter }=50 \\
\text { Height }=50\end{array}$} & $\mathrm{X}$ & 12 \\
\hline & & $\mathrm{Y}$ & 12 \\
\hline & & $\mathrm{Z}$ & 12 \\
\hline
\end{tabular}

Table 2 :3D printing process parameters for the sand specimens.

\begin{tabular}{|l|l|}
\hline Average sand grain size & $140 \mu \mathrm{m}$ \\
\hline Activator content & $0.18 \mathrm{wt} . \%^{*}$ \\
\hline Inhibitor content & $0.4 \mathrm{wt} . \%^{\dagger}$ \\
\hline Print head voltage & $78 \mathrm{~V}$ \\
\hline Layer thickness & $280 \mu \mathrm{m}$ \\
\hline Heating temperature & $305 \mathrm{~K}$ \\
\hline Print resolution & $120-140 \mu \mathrm{m}$ \\
\hline Recoater speed & $130-286 \mathrm{~mm} \cdot \mathrm{s}^{-1}$ \\
\hline
\end{tabular}

Table 3: Process parameters with their ranges and values at two levels.

\begin{tabular}{|c|c|c|c|c|}
\hline Parameter Designation & Process Parameter & Range & Level 1 & Level 2 \\
\hline $\mathrm{X}$ & X-position in job box $(\mathrm{mm})$ & $50-750$ & 50 & 750 \\
\hline $\mathrm{Y}$ & Y-position in job box $(\mathrm{mm})$ & $50-450$ & 50 & 450 \\
\hline $\mathrm{X}_{\mathrm{R}}$ & Print Resolution $(\mu \mathrm{m})$ & $120-140$ & 120 & 140 \\
\hline $\mathrm{RS}$ & Recoater Speed $\left(\mathrm{mm} \cdot \mathrm{s}^{-1}\right)$ & $130-286$ & 130 & 286 \\
\hline
\end{tabular}

\footnotetext{
* Of the sand weight.
}

${ }^{\dagger}$ Of the sand weight. 
Table 4 : Coefficients of process parameter effects on permeability, flexural stress, and density.

\begin{tabular}{|c|c|c|c|c|c|c|c|}
\hline Parameters & Identifiers & $\begin{array}{c}\boldsymbol{P}_{X} \\
\left(\mathbf{G P}^{\ddagger}\right)\end{array}$ & $\begin{array}{c}P_{Y} \\
(\mathbf{G P})\end{array}$ & $\begin{array}{c}P_{Z} \\
(\mathbf{G P})\end{array}$ & $\begin{array}{c}\sigma_{X} \\
(\mathbf{M P a})\end{array}$ & $\begin{array}{c}\sigma_{y} \\
(\mathbf{M P a})\end{array}$ & $\begin{array}{c}\rho \\
\left(\mathbf{k g} \cdot \mathbf{m}^{-3}\right)\end{array}$ \\
\hline Average & $\mathrm{M}$ & 115.6 & 97.1 & 98.6 & 1.913 & 1.969 & 1311 \\
\hline $\mathrm{X}$ & A & -10.3 & -9.8 & -10.4 & 0.119 & 0.106 & 22 \\
\hline $\mathrm{Y}$ & $\mathrm{B}$ & -2.8 & -1.1 & -3.2 & 0.157 & 0.069 & 3 \\
\hline$X_{R}$ & $\mathrm{C}$ & 0.8 & 0.5 & -0.9 & -0.206 & -0.238 & -2 \\
\hline $\mathrm{RS}$ & $\mathrm{D}$ & 19.9 & 15 & 19.8 & -0.325 & -0.406 & -4.8 \\
\hline $\mathrm{X}-\mathrm{Y}$ & $\mathrm{AB}$ & 0.6 & 2.3 & 0.8 & 0.038 & 0.043 & 3 \\
\hline $\mathrm{X}-\mathrm{X}_{\mathrm{R}}$ & $\mathrm{AC}$ & -3.3 & -3.8 & -1.2 & -0.013 & 0.025 & 3 \\
\hline X-RS & $\mathrm{AD}$ & -5.9 & -4.6 & -5.9 & 0.056 & 0.056 & 9 \\
\hline $\mathrm{Y}-\mathrm{X}_{\mathrm{R}}$ & $\mathrm{BC}$ & -0.1 & 0 & -0.4 & -0.075 & -0.013 & -3 \\
\hline Y-RS & $\mathrm{BD}$ & -1.9 & -2.5 & -3.6 & 0.069 & 0.006 & 3 \\
\hline$X_{R}-R S$ & $\mathrm{CD}$ & -1.3 & -2.3 & -2.9 & 0.069 & 0.038 & 6 \\
\hline \multicolumn{2}{|c|}{ Maximum residual errors } & 6 & 9 & 4 & 0.11 & 0.09 & 8 \\
\hline \multicolumn{2}{|c|}{ Minimum } & 89.7 & 72.3 & 71.7 & 1.175 & 1.156 & 1226 \\
\hline \multicolumn{2}{|c|}{ Maximum } & 159.9 & 134.4 & 144.7 & 2.788 & 2.794 & 1383 \\
\hline
\end{tabular}

Table 5 : Calculated mold sample properties for $X_{R}$ and RS values of $140 \mu \mathrm{m}$ and $158 \mathrm{~mm} \cdot \mathrm{s}^{-1}$ according to the model proposed in Table 3

\begin{tabular}{|c|c|c|c|c|c|c|c|}
\hline $\mathbf{X}$ & $\mathbf{Y}$ & $P_{X}($ GP) & $\mathbf{P}_{\mathbf{Y}}(\mathbf{G P})$ & $\mathbf{P}_{\mathrm{Z}}(\mathbf{G P})$ & $\sigma_{\mathbf{X}}(\mathrm{MPa})$ & $\sigma_{\mathbf{y}}(\mathbf{M P a})$ & $\begin{array}{c}\rho \\
\left(\mathbf{k g} \cdot \mathbf{m}^{-3}\right)\end{array}$ \\
\hline-1 & -1 & 115 & 101 & 96 & 1.81 & 1.87 & 1324 \\
\hline 1 & -1 & 95 & 76 & 79 & 1.87 & 1.98 & 1356 \\
\hline-1 & 1 & 111 & 100 & 92 & 1.81 & 1.89 & 1314 \\
\hline 1 & 1 & 93 & 81 & 78 & 2.02 & 2.16 & 1358 \\
\hline \multicolumn{2}{|c|}{ Average } & \multicolumn{3}{|c|}{93.1} & \multicolumn{2}{|c|}{1.92} & 1338 \\
\hline \multicolumn{2}{|c|}{$\begin{array}{l}\text { Standard } \\
\text { deviation }\end{array}$} & \multicolumn{3}{|c|}{12.8} & \multicolumn{2}{|c|}{0.12} & 22 \\
\hline
\end{tabular}

Table 6 : Measured mold sample properties for $X_{R}$ and RS values of $140 \mu \mathrm{m}$ and $158 \mathrm{~mm} \cdot \mathrm{s}^{-1}$

\begin{tabular}{|c|c|c|c|c|c|c|c|}
\hline $\mathbf{X}$ & $\mathbf{Y}$ & $\mathbf{P}_{\mathbf{X}}(\mathbf{G P})$ & $\mathbf{P}_{\mathbf{Y}}(\mathbf{G P})$ & $\mathbf{P}_{\mathbf{Z}}(\mathbf{G P})$ & $\begin{array}{c}\boldsymbol{\sigma}_{\mathbf{X}} \\
(\mathbf{M P a})\end{array}$ & $\begin{array}{c}\boldsymbol{\sigma}_{\mathbf{y}} \\
(\mathbf{M P a})\end{array}$ & $\begin{array}{c}\boldsymbol{\rho} \\
\left(\mathbf{k g} \cdot \mathbf{m}^{-3}\right)\end{array}$ \\
\hline-1 & -1 & 98 & 78 & 76 & 1.70 & 1.85 & 1341 \\
\hline 1 & -1 & 93 & 71 & 69 & 1.85 & 1.90 & 1382 \\
\hline-1 & 1 & 96 & 77 & 80 & 1.85 & 1.90 & 1338 \\
\hline 1 & 1 & 85 & 65 & 66 & 2.20 & 2.00 & 1385 \\
\hline \multicolumn{7}{|c|}{ Average } & \multicolumn{3}{|c|}{1.91} & 1362 \\
\hline \multicolumn{2}{|c|}{$\begin{array}{l}\text { Standard } \\
\text { deviation }\end{array}$} & 11.4 & \multicolumn{2}{|c|}{0.15} & 25 \\
\hline
\end{tabular}

\footnotetext{
$\$$ Commonly used AFS number for gas permeability of sand mold, but does not have the SI or proper scientific
} unit. 
Table A.1 : Average values of permeability, flexural stress, and density for various process parameters.

\begin{tabular}{|c|c|c|c|c|c|c|c|c|c|}
\hline \multicolumn{4}{|c|}{ Level of Process Parameters } & \multirow{2}{*}{$\begin{array}{c}P_{X} \\
(G P)\end{array}$} & \multirow{2}{*}{$\begin{array}{c}P_{Y} \\
(\mathbf{G P})\end{array}$} & \multirow{2}{*}{$\begin{array}{c}P_{Z} \\
(\mathbf{G P})\end{array}$} & \multirow{2}{*}{$\begin{array}{c}\sigma x \\
(\mathbf{M P a})\end{array}$} & \multirow{2}{*}{$\begin{array}{c}\sigma_{y} \\
(\mathbf{M P a})\end{array}$} & \multirow{2}{*}{$\begin{array}{c}\rho \\
\left(\mathrm{kg} \cdot \mathrm{m}^{-3}\right)\end{array}$} \\
\hline$x$ & $\mathbf{Y}$ & $\mathbf{X}_{\mathbf{R}}$ & RS & & & & & & \\
\hline-1 & -1 & -1 & -1 & 95.94 & 81.38 & 79.94 & 2.31 & 2.59 & 1.3581 \\
\hline 1 & -1 & -1 & -1 & 92.69 & 74.38 & 71.69 & 2.39 & 2.56 & 1.3706 \\
\hline-1 & 1 & -1 & -1 & 93.19 & 79.63 & 80.19 & 2.56 & 2.66 & 1.3581 \\
\hline 1 & 1 & -1 & -1 & 92.19 & 81.63 & 75.19 & 2.79 & 2.79 & 1.3831 \\
\hline-1 & -1 & 1 & -1 & 106.94 & 94.88 & 87.19 & 1.94 & 2.02 & 1.3431 \\
\hline 1 & -1 & 1 & -1 & 90.44 & 72.38 & 74.19 & 1.96 & 2.08 & 1.3681 \\
\hline-1 & 1 & 1 & -1 & 103.94 & 93.13 & 85.69 & 1.89 & 2.03 & 1.3306 \\
\hline 1 & 1 & 1 & -1 & 89.69 & 79.63 & 75.94 & 2.06 & 2.27 & 1.3681 \\
\hline-1 & -1 & -1 & 1 & 154.19 & 130.38 & 144.69 & 1.28 & 1.58 & 1.2256 \\
\hline 1 & -1 & -1 & 1 & 127.19 & 104.88 & 112.69 & 1.58 & 1.77 & 1.2756 \\
\hline-1 & 1 & -1 & 1 & 143.69 & 118.63 & 130.19 & 1.80 & 1.67 & 1.2381 \\
\hline 1 & 1 & -1 & 1 & 118.94 & 102.13 & 101.44 & 2.25 & 2.03 & 1.3006 \\
\hline-1 & -1 & 1 & 1 & 159.94 & 134.38 & 140.19 & 1.18 & 1.16 & 1.2331 \\
\hline 1 & -1 & 1 & 1 & 119.69 & 93.38 & 103.44 & 1.43 & 1.44 & 1.2956 \\
\hline-1 & 1 & 1 & 1 & 149.19 & 122.63 & 123.94 & 1.40 & 1.19 & 1.2331 \\
\hline 1 & 1 & 1 & 1 & 111.19 & 90.63 & 90.44 & 1.80 & 1.66 & 1.3081 \\
\hline
\end{tabular}

